\title{
Estimation of in-lab sampling rates and uptake kinetics for 24 polar organic micro pollutants by polar organic chemical integrative sampler "POCIS"
}

\begin{abstract}
Pesticides are between the major contaminants that invade aquatic environments. Pesticides monitoring programs were usually conducted using active sampling method in environmental water sites to evaluate the real state of the aquatic media. Polar Organic Chemical Integrative Sampler (POCIS) was recently used for the monitoring of polar pesticides residues in environmental water. The application requires its prior calibration in order to determine the sampling rate "Rs" needed to evaluate the real water concentration of analytes. This paper generates the "Rs" values in water for 24 pesticides never been generated previously. The POCIS laboratory-calibration was performed in glass beakers on the basis of static renewal exposure under stirred conditions for 25 days. The accumulation kinetics of these pesticides was evaluated and the Rs values found varied from 0.0186 to $0.316 \mathrm{~L}$ day -1 with $\mathrm{RSD}<24 \%$. The effect of hydrophobicity on sampling rates (Rs) was also evaluated. Furthermore, we evaluated the applicability of deuterated Atrazine (ATR d5) as Performance Reference Compounds (PRC) to account for between-site variation. High performance liquid chromatography (HPLC) coupled with triple quadrupole tandem mass spectrometry (LC-MS/MS) was used for the analysis.
\end{abstract}

Keywords: polar pesticide, passive sampler, sampling rate, hydrophobicity, LC$\mathrm{MS} / \mathrm{MS}$
Volume 3 Issue 2 - 2018

\author{
Al Ashi Aisha, ${ }^{1,2,3}$ Kouzayha Abir, ${ }^{1,2}$ Rifai \\ Ahmad,,'2 Abdel Rahman Rabaa,' Budzinski \\ Hélène, ${ }^{3}$ Jaber Farouk ${ }^{1,2}$ \\ 'Faculty of Sciences, Laboratory of Analysis of Organic \\ Compounds, Lebanese University, Syria \\ ${ }^{2}$ National Council for Scientific Research CNRS - Lebanese \\ Atomic Energy Commission LAEC - Laboratory for Analysis of \\ Organic Compound (LAOC), Syria \\ ${ }^{3}$ Faculty of Sciences, University of Bordeauxc, France
}

Correspondence: Al Ashi Aisha Lebanese University, Faculty of Sciences, Laboratory for Analysis of Organic Compounds, Lebanese University, Beirut 6573, Lebanon, Syria, Tel +96I-3584|3-4,Email aishaashi@hotmail.com

Received: January 23, 2018| Published: April 05, 2018

\section{Introduction}

Pesticides are the most recurrent source of episodic and chronic pollution problems observed in aquatic systems. Indeed, their "arbitrary" use by farmers enhance their dispersion in the atmosphere, to be scattered by the wind, to fall with the rain directly on water bodies and soils where they are infiltrated into aquatic environments. Pesticides are now the source of diffuse pollution that contaminates all inland waters: rivers, groundwater and coastal areas. The discharge of these contaminants in water makes it unfit for consumption or may degrade some of its properties. ${ }^{1}$ They would be potentially responsible of long-term carcinogenic diseases. To evaluate the risk of such compounds, their levels in environmental water should be estimated. Therefore, monitoring water quality seems a crucial step. According to the European Directive, this monitoring requires powerful tools to evaluate the average concentration of these pesticides in water taking into account all environmental variables. The passive sampling, represent recently an alternative approach to monitoring programs that rely on collecting grab samples (active sampling) or aquatic organisms (biological sampling). In contrast to grab sampling, passive sampling enables the determination of Time Weighted Average (TWA) concentration of contaminants present in the dissolved phase of water over extended sampling periods; it also permits the detection of trace and ultra-trace contaminants of $\mu \mathrm{g}$ $\mathrm{L}^{-1}$ or $n g \mathrm{~L}^{-1}$ due to its pre-concentration ability. Passive sampling is also capable to detect all episodic events that could be happened in the environment during sampling period and offers significant handling, use and economic benefits..$^{2-5}$ The accumulation through passive samplers is based on a diffusion phenomenon of analytes from the aquatic media to the sorbent phase through the different compartments of the device. Among the passive samplers available, the most widely used for sampling polar organic pesticides is the polar organic chemical integrative sampler (POCIS). It is usually used for sampling hydrophilic pesticides with a partition coefficient octanolwater (log kow) lower than $4 .^{6-9}$ This device was characterized by its ability to determine the TWA value for each target compound over the exposition duration. Thus, uptake rate (Rs) for the compounds of interest must be determined either theoretically or by experimental calibrations. ${ }^{10}$ Sampling rate represents the volume of water depurated per time unit. The calibration experiment consists on the exposition of the POCIS in contaminated water under stirred conditions to evaluate the mass of contaminants accumulated in its sorbent phase used then to determine their sampling rates. This specific compound value depends on the physico-chemical properties of the chemicals (e.g. molecular weight, structure and hydrophobicity), on the calibration experiment conditions (e.g. temperature, $\mathrm{pH}$, salinity, biofouling) and on the device configuration (e.g. type of membrane, sorbent phase). ${ }^{3,5,11}$ In literature, almost generated Rs were for herbicides while our target compounds belonged mainly to insecticide and fungicide classes.

The aim of the present work was to

I. Study the uptake kinetics of 24 pesticides by POCIS sampler, in order to determine their sampling rates based on static laboratory calibration under stirred conditions,

II. To evaluate the correlation between the sampling rates and the $\log$ kow factor,

III. To study the behavior of ATR d5 proposed as PRC compound in the sorbent phase prior to exposure.

\section{Materials and methods}

\section{Theory and modeling}


POCIS consists of a solid-phase sorbent or a mixture of sorbents enclosed between two hydrophilic microporous Polyether Sulfone (PES) membranes. ${ }^{12,13}$ To prevent sorbent loss, these two membranes were compressed with metallic rings using thumb screws. The uptake of contaminants through POCIS from water to the receiving sorbent is used for sampling a wide range polarity of contaminants. ${ }^{11,14}$ The accumulation of chemicals generally followed first order kinetic followed by a curvilinear and equilibrium partitioning stage. ${ }^{12,15}$ During the integrative phase of uptake, residues are accumulated linearly relative to time ${ }^{16}$ and the relationship between the analytes accumulated mass in the sampler receiving phase and its concentration in the surrounding water is given by the following Eq. $1 ;{ }^{17}$ For each compound:

$$
\mathrm{C}_{\text {POCIS }}=\mathrm{C}_{\mathrm{w}} \cdot \mathrm{K}_{\mathrm{u}} \cdot \mathrm{t}
$$

CPOCIS $\left(\mathrm{ng} \mathrm{g}^{-1}\right)$ is the accumulated concentration of pesticides in
POCIS during the exposure time $\mathrm{t}, \mathrm{Cw}\left(\mathrm{ng} \mathrm{L}^{-1}\right)$ is the Time-Weighted Average (TWA) concentration of the analyte in the water phase, and $\mathrm{ku}\left(\mathrm{L} \mathrm{g}^{-1} \mathrm{~d}^{-1}\right)$ is the accumulation rate constant between the two phases (CPOCIS/CWater) per day. During calibration experiments, the samplers are exposed for a defined time to a constant analyte concentration in the water. The mass of accumulated compounds evaluated in each POCIS depend on the new mass of sorbent contained in the POCIS (mphase), hence the sampling rate Rs can be derived by Eq. $2:{ }^{17}$

$$
\mathrm{R}_{\mathrm{s}}=\mathrm{k}_{\mathrm{u}} * \mathrm{~m}_{\text {phase }}
$$

Eq. 1 is considered valid from the time that steady-state flux into the sampler has been established to the time that sampler concentrations reach about half their equilibrium concentrations $\left(\mathrm{t}_{1 / 2}\right) \cdot{ }^{17} \mathrm{t}_{1 / 2}$ is defined by Eq.3: ${ }^{17}$

$$
\mathrm{t}_{1 / 2}=\ln 2 / \mathrm{ke}
$$

\begin{tabular}{|c|c|c|c|c|c|c|c|c|}
\hline Pesticides & Type' & Groupa & Cas numbera & $\begin{array}{l}\mathrm{Mw}^{\mathrm{a}}(\mathrm{g} \\
\left.\mathrm{mol}^{-1}\right)\end{array}$ & $\begin{array}{l}\log \\
\text { kow a }\end{array}$ & $\begin{array}{l}\text { Water } \\
\text { Solubility } \\
\left(\mathrm{mg} \mathrm{L}^{-1}\right)\end{array}$ & $\begin{array}{l}\text { POCIS } \\
\text { recovery (\%) } \\
(n=3) \text { (RSD) }\end{array}$ & $\begin{array}{l}\text { Water } \\
\text { recovery \% } \\
(n=2)(R S D)\end{array}$ \\
\hline Omethoate & Insecticide & Organophosphate & $1113-02-6$ & 213.2 & -0.74 & 10000 & $42.32(8)$ & $78.26(6)$ \\
\hline Dicrotophos & Insecticide & Organophosphate & $|4|-66-2$ & 237.19 & -0.5 & 1000000 & $69.29(5)$ & $67.14(10)$ \\
\hline Oxamyl & Insecticide & Carbamate & $23135-22-0$ & 219.26 & -0.44 & 148100 & $50.42(9)$ & $72.19(5)$ \\
\hline Propoxur & Insecticide & Carbamate & $1 \mid 4-26-1$ & 209.24 & 0.14 & 1800 & $93.15(7)$ & $79.89(3)$ \\
\hline Oxadixyl & Fungicide & Phenylamide & $77732-09-3$ & 278.3 & 0.65 & 3400 & $70.14(10)$ & $73.98(5)$ \\
\hline Cymoxanil & Fungicide & Cyanoacetamide oxime & $57966-95-7$ & 198.18 & 0.67 & 780 & $64.27(8)$ & $82.15(6)$ \\
\hline Phosphamidon & Insecticide & Organophosphate & $|3| 7|-2|-6$ & 299.69 & 0.795 & 1000000 & $109.62(12)$ & $82.48(8)$ \\
\hline Methacrifos & Insecticide & Organothiophosphate & $62610-77-9$ & 240.22 & 1.53 & 400 & $74.15(6)$ & $90.12(4)$ \\
\hline Heptenophos & Insecticide & Organophosphate & $23560-59-0$ & 250.6 & 2.32 & 2200 & $84.76(4)$ & $91.38(6)$ \\
\hline Methidathion & Insecticide & Organothiophosphate & $950-37-8$ & 302.3 & 2.57 & 240 & $85.64(15)$ & $80.16(6)$ \\
\hline Atrazine & Herbicide & Triazine & $1912-24-9$ & 215.68 & 2.7 & 35 & $90.21(16)$ & $87.31(11)$ \\
\hline Pyrimethanil & Fungicide & Anilinopyrimidine & 53|| $2-28-0$ & 199.11 & 2.84 & $|2|$ & I I 2.98 (I8) & $72.19(7)$ \\
\hline Myclobutanil & Fungicide & Triazole & $8867 \mid-89-0$ & 288.78 & 2.89 & 132 & $94.73(19)$ & $82.29(6)$ \\
\hline Etrimphos & Insecticide & Organothiophosphate & $38260-54-7$ & 292.29 & 2.94 & 40 & $72.32(13)$ & $74.36(8)$ \\
\hline Boscalid & Fungicide & Carboxamide & $188425-85-6$ & 343.21 & 2.96 & 4.6 & $88.61(7)$ & $83.82(5)$ \\
\hline Cyproconazole & Fungicide & Triazole & $94361-06-5$ & 291.78 & 3.09 & 93 & $96.03(9)$ & $85.12(4)$ \\
\hline Mepanipyrim & Fungicide & Anilinopyrimidine & I I0235-47-7 & 223.27 & 3.28 & 2.08 & II3.46 (I3) & $71.63(7)$ \\
\hline Fenamiphos & Insecticide & Organophosphate & $22224-92-6$ & 303.36 & 3.3 & 345 & $93.98(10)$ & $102.08(9)$ \\
\hline Kresoxim-ME & Fungicide & Strobilurin & |43390-89-0 & 313.35 & 3.4 & 2 & $65.36(20)$ & $78.31(3)$ \\
\hline Fenhexamide & Fungicide & Hydroxyanilide & $126833-17-8$ & 302.2 & 3.51 & 20 & $79.28(3)$ & $81.51(4)$ \\
\hline Triazophos & Insecticide & Organophosphate & $24017-47-8$ & 313.3 & 3.55 & 35 & $74.42(12)$ & $77.42(10)$ \\
\hline Bupirimate & Fungicide & Pyrimidinol & $4 \mid 483-43-6$ & 316.42 & 3.68 & 13.06 & $106.52(19)$ & $79.36(3)$ \\
\hline Fenarimol & Fungicide & Pyrimidine & $60168-88-9$ & 331.2 & 3.69 & 13.7 & $108.92(13)$ & $82.26(7)$ \\
\hline Cadusafos & Insecticide & Organothiophosphate & 95465-99-9 & 270.39 & 3.85 & 245 & $80.37(8)$ & $75.18(6)$ \\
\hline
\end{tabular}

Table I Physicochemical properties and recoveries of selected pesticides classified with increasing log kow

Molecular weight (Mw), n-Octanol/water partition coefficient kow

Source: IUPAC footprint pesticide database 
Where ke is the overall exchange rate constant or elimination rate constant $\left(\right.$ day $\left.^{-1}\right)$, calculated when the accumulated substances released from the receiving phase.

Since the uptake rates into the receiving phase varies with the physico-chemical properties of the target analytes and with the experimental and environmental conditions (e.g. temperature, biofouling, turbulence...), a drawback seems then necessary to correct these in-lab Rs. This correction is made using Performance Reference Compounds "PRC" which are currently difficult to identify for POCIS. ${ }^{3,12,14,18-20}$ PRC has moderate to high fugacity from the sorbent, they are analytically non-interfering chemicals (e.g., deuterium or ${ }^{13} \mathrm{C}$ labeled compounds and native compounds not found in the environmental system) that are added to a passive sampler phase prior to exposure. ${ }^{19,21}$ In case of isotropic exchange, PRCs provide important information about the role of environmental conditions on the loss and uptake rates of analyte. ${ }^{21}$ Under these conditions of isotropic exchange, the elimination rate constant from the sorbent "ke" of a PRC can be determined with the first order kinetic relationship: ${ }^{21}$

$$
\text { ke PRC }=\operatorname{In}(\mathrm{CPRCO} / \mathrm{CPRCt}) / \mathrm{t}
$$

Where CPRC $(\mathrm{t})$ is the residual concentration $\left(\mu \mathrm{g} \mathrm{g}^{-1}\right)$ of PRC in the receiving phase after an exposure time $(\mathrm{t})$ and $\mathrm{C}_{\mathrm{PRC} 0}$ is the concentration of PRC spiked into the receiving phase before the exposure.

Table 2 (A) SRM transitions and ESI-MS/MS optimized parameters for 24 pesticides

\begin{tabular}{|c|c|c|c|c|c|c|c|c|}
\hline Pesticides & $\operatorname{tr}(\min )$ & Prec Ion & Dwell & Frag (V) & $\begin{array}{l}\text { Quantification } \\
\text { lon I }\end{array}$ & $\begin{array}{l}\text { Qualification } \\
\text { lon2 }\end{array}$ & CEI (V) & CE2 (V) \\
\hline Omethoate & 3.429 & 214.1 & 10 & 90 & 183 & 125 & 5 & 15 \\
\hline Dicrotophos & 4.473 & 238.1 & 10 & 60 & 127 & 112.1 & 15 & 5 \\
\hline Oxamyl & 3.621 & 237 & 10 & 60 & 90 & 72 & 5 & 15 \\
\hline Propoxur & 12.744 & 210 & 10 & 60 & 168.1 & 111 & 5 & 10 \\
\hline Oxadixyl & 10.156 & 279 & 10 & 90 & 219 & 133 & 5 & 20 \\
\hline Cymoxanil & 7.909 & 199 & 10 & 50 & 128 & 111 & 2 & 10 \\
\hline Phosphamidon & 10.509 & 300 & 10 & 100 & 174 & 127 & 5 & 20 \\
\hline Methacrifos & 20.461 & 241 & 5 & 60 & 209 & 124.9 & 5 & 20 \\
\hline Heptenophos & 18.909 & 251 & 5 & 80 & 127 & 109 & 5 & 30 \\
\hline Methidathion & 20.313 & 303 & 5 & 60 & 145 & 85 & 5 & 15 \\
\hline Atrazine & 18.426 & 216 & 5 & 150 & 174 & 104 & 10 & 30 \\
\hline Pyrimethanil & 21.88 & 200.1 & 5 & 140 & 107 & 80.1 & 25 & 20 \\
\hline Myclobutanil & 24.624 & 289.2 & 5 & 150 & 125.1 & 70.2 & 20 & 15 \\
\hline Etrimphos & 27.083 & 293.1 & 5 & 110 & 265.1 & 125 & 12 & 25 \\
\hline Boscalid & 23.433 & 343.1 & 5 & 130 & 307.1 & 139.8 & 15 & 15 \\
\hline Cyproconazole & 25.064 & 292.1 & 5 & 120 & 125.1 & 70.2 & 20 & 20 \\
\hline Mepanipyrim & 25.187 & 224 & 5 & 120 & 106 & 77 & 25 & 35 \\
\hline Fenamiphos & 25.485 & 304.1 & 5 & 120 & 234 & 217.1 & 15 & 20 \\
\hline Kresoxim-ME & $26.26 I$ & 314 & 5 & 40 & 235 & 222 & 10 & 10 \\
\hline Fenhexamide & 25.086 & 302.1 & 5 & 90 & 97 & 55.1 & 25 & 30 \\
\hline Triazophos & 23.649 & 314.1 & 5 & 150 & 286.2 & 162.2 & 10 & 20 \\
\hline Bupirimate & 25.529 & 317 & 5 & 150 & 166 & 108 & 20 & 20 \\
\hline Fenarimol & 25.15 & 331 & 5 & 130 & 268 & 139 & 30 & 40 \\
\hline Cadusafos & 26.524 & 271.1 & 5 & 60 & 159 & 130.9 & 7 & 20 \\
\hline
\end{tabular}

Table 2 (B) SRM transitions and ESI-MS/MS optimized parameters for internal standards compounds

\begin{tabular}{lllllll}
\hline Etalons & $\operatorname{tr}(\mathbf{m i n})$ & Prec Ion & Dwell & $\begin{array}{l}\text { Frag } \\
(\mathbf{V})\end{array}$ & $\begin{array}{l}\text { Prod } \\
\text { lon }\end{array}$ & $\begin{array}{l}\text { CE } \\
(\mathbf{V})\end{array}$ \\
\hline DIAd5 & 5.599 & 179 & 10 & 100 & 137 & 14 \\
ATR d5 & 17.391 & 221.1 & 5 & 100 & 179.1 & 20 \\
TPP & 25.833 & 327.1 & 5 & 100 & 215 & 25 \\
\hline
\end{tabular}

\section{Materials, chemicals and POCIS samplers}

All pesticides included in this study (purity $>90 \%$ ) were purchased from Dr. Ehrenstorfer GmbH (Augsburg, Germany), Sigma-Aldrich (Steinheim, Germany), Fluka (Germany), Supelco (Germany) and Chemservice (westchester PA). Triphenylphosphate compound (TPP) and deuterated labeled compound, atrazine d5 (purity $>98 \%$ ) were obtained from Sigma-Aldrich (Steinheim, Germany) and were used as internal and surrogate standard respectively. Working solutions of 
individual compounds and mixtures were prepared by appropriate dilution of the stock solutions in methanol and stored then in the dark at $-4^{\circ} \mathrm{C}$. Standard working mixture of pesticides $\left(1 \mathrm{mg} \mathrm{L}^{-1}\right)$ prepared in methanol was used for the experiment.

Methanol and dichloromethane (HPLC grade) were supplied by Sigma-Aldrich (Steinheim, Germany). Acetonitrile (LC/MS grade) was purchased from Sigma-Aldrich (USA). Water chromasolv (LC/ MS grade) used for LC-MS/MS analysis was generated from FLUKA (Switzerland). Formic acid (purity $>98 \%$ ) and ammonia solution were obtained from England, BDH laboratories. The POCIS was built using Oasis HLB bulk sorbent (average particle diameter: $60 \mu \mathrm{m}$ ) and hydrophilic polyethersulfone (PES) SUPOR 100 membranes disc filters $(0.1 \mu \mathrm{m}, 90 \mathrm{~mm}$ membrane diameter) purchased from Waters (Mildford, MA, USA) and PALL (Saint-Germain-en-Laye, France), respectively. Commercial cartridges packed with Oasis ${ }^{\mathrm{TM}}$ HLB (divinylbenzene/N-vinylpyrrolidone copolymer, $60 \mathrm{mg}, 3 \mathrm{~cm}^{3}$ ) were purchased from Waters (Mildford, MA, USA). The sampler's stainless steel POCIS were handmade, glass polypropylene SolidPhase Extraction (SPE) tubes $(6 \mathrm{~mL})$ with polytetrafluoroethylene (PTFE) frits (20 $\mu \mathrm{m}$ porosity) were purchased from Supelco (SaintQuentin Fallavier, France).

\section{Physico-chemical properties of compounds}

The group of pesticides included in this study was selected on the basis of those mostly present in Lebanese aquatic environment They comprise a group of 24 chemicals belonging to different pesticide categories: insecticides (cadusafos, dicrotophos, etrimfos, fenamiphos, heptenophos, methacrifos, methidathion, omethoate, oxamyl, phosphamidon, propoxur and triazophos), fungicides (boscalid, bupirimate, cymoxanil, cyproconazole, fenarimol, fenhexamide, kresoxim-ME, mepanipyrim, myclobutanil, oxadixyl, and pyrimethanil) and herbicide (Atrazine). DIA d5 (deuterated deisopropyl atrazine) and Atrazine d5 were selected as PRCs for investigation of the offload behavior. All the investigated compounds in this study are polar except for dicrotophos, omethoate and oxamyl which are too polar with $\log$ kow $<0$. They were introduced in this paper in order to test the applicability of POCIS and to evaluate their diffusion kinetic in a device qualified for hydrophilic compounds. The SPE recoveries on POCIS sorbent phase established in our laboratory were all above $70 \%$ except for cymoxanil $(64.27 \%)$, kresoxim-ME $(65 \%)$, omethoate $(42 \%)$ and oxamyl $(50.42 \%)$. Physiochemical properties of the selected pesticides are shown in Table 1.

\section{Treatment of the receiving phase}

Prior to use, the Oasis HLB sorbent was rinsed three times successively with methanol and then dried under vaccum for one night under hood. When dried, the sorbent phase was then weighted and fortified with predicted PRC with a concentration equal to $2 \mu \mathrm{g}$ per $g$ of sorbent. DIA d5 and ATR d5 were the PRCs used in this experiment. After this fortification step, the sorbent was then covered with few $\mathrm{mL}$ of $\mathrm{MeOH}$ which has been evaporated at its boiling point using Rotavap instrument (Switzerland). When the organic solvent is totally evaporated and the sorbent returned to its initial appearance, the spiked sorbent became then ready to use. After exposure, each POCIS was opened and the sorbent was recovered from the PES membranes with ultrapure water and transferred into 6 $\mathrm{mL}$ empty glass SPE tube with a polyethylene frit and packed under vacuum by using the Visiprep SPE manifold. The sorbent was dried for $30 \mathrm{~min}$ under vacuum. Pesticides were extracted with $5 \mathrm{~mL}$ of methanol, $5 \mathrm{ml}$ of methanol/dichloromethane (v/v: 50/50) and $5 \mathrm{~mL}$ of dichloromethane. The eluate was then evaporated under a gentle stream of nitrogen and reconstituted in $1 \mathrm{~mL}$ of acetonitrile and the extract was filtered directly into an analysis vial. All extracts were spiked before the analysis with $20 \mu \mathrm{L}$ of $1 \mathrm{mg} \mathrm{L}^{-1}$ of TPP prepared in acetonitrile. Sorbent was then dried under vaccum and weighted. All results were corrected by using the real mass of sorbent in each exposed sampler.

\section{Experimental calibration}

The POCIS calibration was conducted in triplicate in 8 simultaneous glass beakers containing $2 \mathrm{~L}$ of mineral water $(\mathrm{pH}=7.1 \pm 0.9$ and Conductivity $\sigma=0.029 \mathrm{~S} \mathrm{~m}^{-1}$ ) placed at room temperature $20 \pm 2^{\circ} \mathrm{C}$ for 25 days. The exposition water was fortified with $100 \mathrm{ng} \mathrm{L}^{-1}$ of a mixture of 24 compounds including Atrazine. Magnetic stirrer was used to gently mix the water. Beakers were covered with aluminum foil. The water was replaced by freshly fortified water every 24 hours to keep constant water concentration during the whole experiment duration. Along the experiment, two beakers $(2 \mathrm{~L})$ of non fortified mineral water containing each 3 POCIS considered as negative control to assess contamination during the experiment and one beaker containing only fortified water considered as positive control in order to correct for sorption, volatilization or degradation during exposure were conducted. POCIS $(\mathrm{n}=3)$ were retrieved at days $1,3,5,7,10,15$, 20 and 25 days. Water samples of $300 \mathrm{~mL}(\mathrm{n}=2)$ were collected at day 0 and 25 and extracted using SPE workstation. The HLB cartridges were successively pre-conditioned with $3 \mathrm{ml}$ methanol and then $3 \mathrm{ml}$ of water. Prior to extraction, each sample was fortified with $50 \mu 1$ of ATR d5 ( $\left.1 \mathrm{mg} \mathrm{L}^{-1}\right)$. The samples were percolated through the cartridges under vaccum. After the percolation step, the sorbent was dried under vacuum and then eluted with $3 \mathrm{ml}$ of methanol, $3 \mathrm{ml}$ of methanol/ dichloromethane mixture $(50 / 50 \mathrm{v} / \mathrm{v})$ and $3 \mathrm{ml}$ of dichloromethane. The extraction of water samples showed that recoveries for targeted compounds varied between 67 and $102 \%$ with RSD $<20 \%$ (Table 1), so no degradation phenomenon exist however, a partial adsorption on the wall of the glass beaker may be occurred.

\section{Liquid chromatography mass spectrometry analysis}

Chromatographic separation for the analytes was carried out using an HPLC system (Agilent Series 1200) coupled with a 6410 Triple Quad LC/MS system equipped with an Electro spray Ionization Source (ESI) operating in positive and negative mode. Acquisitions were performed in Multiple Reactions Monitoring (MRM) mode. Detection included two ionization transitions for each analyte, one for quantification and other for confirmation. The instrumental limits of quantification were between $1 \mu \mathrm{g} \mathrm{L}^{-1}$ and $10 \mu \mathrm{g} \mathrm{L}^{-1}$ for all pesticides studied in this paper. Reverse phase $\mathrm{C}-18$ analytical column of 250 $\mathrm{mm} \times 3.0 \mathrm{~mm} \times 5 \mu \mathrm{m}$ (ZORBAX SB, Agilent Technologies) was used for these 24 compounds separation in addition to internal and surrogate standards. Vials were kept at ambient temperature until analysis. Compounds were separated using LC/MS grade water and methanol buffered with ammonium formate $(3 \mathrm{mM})$ following

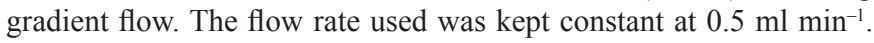
The re-equilibration time was $15 \mathrm{~min}$. The maximum sensitivity of target compounds is obtained through a careful optimization of all MS parameters within Flow Injection Analysis (FIA) of $1 \mathrm{mg} \mathrm{L}^{-1}$ of standard solution of individual compound in methanol. The parameters optimized were: fragmentor Voltage (V), Collision Energy (CE) and polarity mode which remained positive for all selected compounds. 
The values of the parameters and the SRM transitions selected are shown in Table 2. Dwell time values per each SRM transition and signal-to-noise $(\mathrm{S} / \mathrm{N})$ ratio were also optimized (Table $2 \mathrm{~A})$ (Table 2B).

\section{Results and discussion}

\section{POCIS calibration results}

Uptake curves of the pesticides were constructed by fitting the concentration factor versus-time data. The concentration factor is equal to the concentration of pesticides accumulated in POCIS receiving phase versus their concentration in water. The curves were forced through the origin to count any burst or lag effect. From the trends of these kinetic curves, we distinguished 3 types of accumulations (Figure 1). Group 1 (a) made up of 14 compounds; their uptake followed a linear pattern throughout the 25-days exposure. Compounds (log kow) are boscalid (2.96), bupirimate (3.68), cadusafos (3.85), cymoxanil (0.67), etrimfos (2.94), fenamiphos (3.3), heptenphos (2.32), kresoxim-ME (3.4), methacrifos (1.53), methidathion (2.57), oxadixyl (0.65), phosphamidon (0.795), propoxur (0.14) and pyrimethanil (2.84). Group $2(b, c)$ made up of 7 compounds presenting a curvilinear accumulation with an equilibrium state reached at the end of the exposure and for which the POCIS can supply TWA concentrations as described in the model from Alvarez 2007 (Alvarez et al. 2007). Group 2(b) is illustrated by 3 compounds presenting linear pattern until the day 10 of exposure as dicrotophos $(-0.5)$, omethoate $(-0.74)$ and oxamyl $(-0.44)$ while the linear phase for group 2(c) illustrated by cyproconazole (3.09), fenarimol (3.69), fenhexamide (3.51) and myclobutanil (2.89) appeared longer, close to 15 days. Group 3(d) made up of 2 compounds, mepanipyrim (3.28) and triazophos (3.55). As shown in Figure 1D, the accumulation of these both compounds was interrupted with a lag phase phenomenon in the first 5 days of exposure. According to Ibrahim et al. ${ }^{22}$ the lag phase is the time attributed for the compound to initially pass through the diffusive barriers (water boundary layer, water in membrane pores and the membrane). ${ }^{18,22}$ Vermeirssen et al..$^{23}$ suggested that lag effect is mainly related to compounds' log kow and higher is the log kow, higher is the accumulation in the PES membranes increasing lag phase effect. ${ }^{23}$ However, in this study most of the compounds with $\log$ kow $>3$ presented linear accumulation with no lag effect. Thus, we suggested that this phenomenon may be due not only to the compound's log kow but also to their molecular weight or to agitation speed in the calibration container. All of these factors need more investigations.

Figure 1 illustrates the different types of kinetic accumulations $(\mathrm{Cf}=\mathrm{f}(\mathrm{t}))$. The slope of each linear trend corresponding to the accumulation rate constant was used to evaluate the compounds' specific sampling rate (Eq. 2). To keep being in the linear phase, the exposition duration should be lower than the half-time factor $\left(t_{1 / 2}\right)$. The half-time $t_{1 / 2}$ factor was estimated depending on the elimination rate constant of each compound using equation 3 in section 2.1, which is rarely if ever indicated in the literature. According to Vrana, ${ }^{11} \mathrm{t} 1_{12}$ corresponds to the time when the uptake of an analyte is linear and integrative until the concentration factor of the sampler reaches half saturation. ${ }^{16}$ It is a very delicate criterion for providing the optimal exposure duration of POCIS since, it cans changes dramatically with a small variation in a kinetic point. ${ }^{24}$ For compounds showing linear pattern, POCIS can always supply TWA concentrations providing that the device has been exposed higher than $t_{1 / 2}$ compounds' value. For compounds showing lag effect in their accumulation curves (group3), the ke and the $t_{1 / 2}$ values could not be estimated, so other sampler device should be used for sampling as these compounds. The accumulation constants "ku", the correlation coefficients of these linear regressions, the specific compound $t_{1 / 2}$ and sampling rates values determined for $200 \mathrm{mg}$ of sorbent in $\mathrm{L}$ day $^{-1}$ were reported in Table 3. Rs values varied from 0.0186 for omethoate to 0.316 for Oxadixyl with RSD < $22 \%$. Compounds with $3<\log$ kow $<4$ as bupirimate (3.68), cadusafos (3.85), fenamiphos (3.3) and kresoxim-ME (3.4) were integratively and linearly accumulated through POCIS during 25-days with high correlation coefficient (Data of accumulation kinetics are shown in supplementary material). However, we also found that some compounds may have too close log kow but different Rs values as with oxadixyl (0.65) and cymoxanil (0.67) with close log kow while sampling rates were 5 times higher for oxadixyl than cymoxanil. These results suggested that kow is not an enough powerful descriptor able to predict sampling rates for polar compounds with diverse chemical functional groups. ${ }^{13,24}$ On the other hand, as shown with Mazella et al. ${ }^{3}$ lowest sampling rates were generated for the most polar compounds in the series (Omethoate), which confirmed the poor efficiency of POCIS device for sampling too polar compounds. Omethoate (group2) present linear accumulation $\left(\mathrm{Rs}=0.018 \mathrm{~L} \mathrm{day}^{-1}\right)$ followed by a desorption phenomenon at day 10 of the experiment.
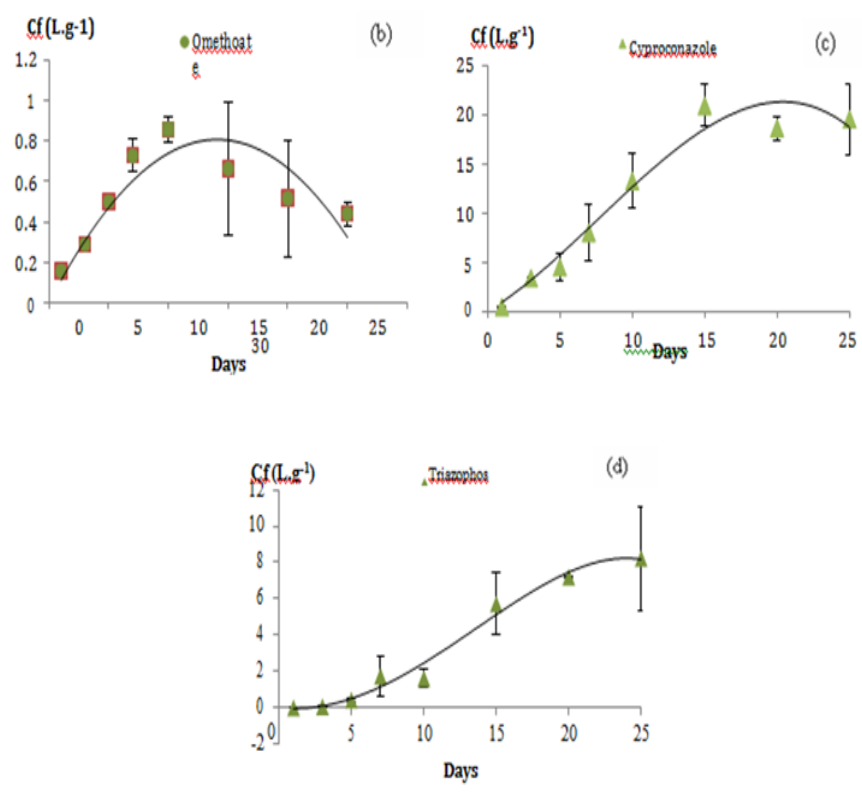

Figure I The 3 types of pesticide accumulation in the POCIS receiving phase illustrated by

a. Etrimphos (groupl)

b. Omethoate and oxamyl (group2)

c. Cyproconazole (group2)

d. Triazophos (group3)

The $t_{1 / 2}$ values found for these 24 pesticides varied from 3 to 150 days. No significant relationship linking the $t_{1 / 2}$ factor to the compounds molecular masses was found as shown with Morin et al. ${ }^{24}$ The comparison between methacrifos and boscalid with molecular weight equal to 240.22 and $343.21 \mathrm{~g} \mathrm{~mol}^{-1}$ respectively showed close $t_{1 / 2}$ values. However, molecular weight was found inversely proportional to the target compound diffusion coefficient affecting 
therefore the compound's uptake rates. But, in this study no discernible linear relationship between molecular weight and sampling rate was observed. A similar result was reported by MacLeod et al. ${ }^{25}$ and Bartlet Hunt. ${ }^{10}$ In all cases, strong relationships $\left(r^{2}>0.936\right)$ between the mass of pesticides accumulated in POCIS and time (Table 3). Based on the calculated slope for each pesticide uptake, we assumed that POCIS works as an integrative sampler for almost compounds in this series ( $92 \%$ of all compounds).

Table 3 Uptake rate constants "ku" of the linear regressions with linearity over 25 days and sampling rates of 24 pesticides classified by increasing log kow

\begin{tabular}{|c|c|c|c|c|c|c|}
\hline Pesticides & Log kow & $\mathbf{t}_{1 / 2}$ (day) & $\mathrm{Ku}\left(\mathrm{L} \mathrm{g}^{-1} \mathrm{~d}^{-1}\right)$ & Rs $\left(\right.$ L day da $\left.^{-1}\right)$ & $\mathbf{r}^{2}$ & RSD (\%) $(n=3)$ \\
\hline Omethoate $^{\mathrm{b}}$ & -0.74 & 4 & 0.093 & 0.0186 & 0.952 & 22 \\
\hline Dicrotophos $^{b}$ & -0.5 & 4 & 1.003 & 0.2 & 0.982 & 14 \\
\hline Oxamyl ${ }^{b}$ & -0.44 & 4 & 0.493 & 0.098 & 0.98 & 16 \\
\hline Propoxur & 0.14 & 6 & 1.351 & 0.27 & 0.989 & 15 \\
\hline Oxadixyl & 0.65 & 12 & 1.583 & 0.316 & 0.936 & 15 \\
\hline Cymoxanil & 0.67 & 9 & 0.356 & 0.071 & 0.989 & 14 \\
\hline Phosphamidon & 0.795 & 5 & 1.431 & 0.286 & 0.971 & 15 \\
\hline Methacrifos & 1.53 & 5 & 0.736 & 0.147 & 0.982 & 18 \\
\hline Heptenophos & 2.32 & 6 & 1.294 & 0.259 & 0.987 & 17 \\
\hline Methidathion & 2.57 & 6 & 0.896 & 0.179 & 0.979 & 19 \\
\hline Atrazine & 2.7 & 17 & 1.3 & 0.26 & 0.993 & 18 \\
\hline Pyrimethanil & 2.84 & 8 & 0.861 & 0.172 & 0.977 & 19 \\
\hline Myclobutanila & 2.89 & 9 & 1.179 & 0.23 & 0.974 & 17 \\
\hline Etrimfos & 2.94 & 8 & 0.54 & 0.108121 & 0.982 & 24 \\
\hline Boscalid & 2.96 & 6 & 0.665 & 0.133 & 0.963 & 20 \\
\hline Cyproconazole $^{a}$ & 3.09 & 5 & 1.307 & 0.261 & 0.97 & 18 \\
\hline Mepanipyrim & 3.28 & Lag & lag & lag & lag & Lag \\
\hline Fenamiphos & 3.3 & 10 & 0.801 & 0.16 & 0.991 & 17 \\
\hline Kresoxim-ME & 3.4 & 8 & 0.549 & 0.1099 & 0.982 & 23 \\
\hline Fenhexamid ${ }^{a}$ & 3.51 & 5 & 1.258 & 0.251 & 0.975 & 17 \\
\hline Triazophos & 3.55 & Lag & lag & lag & lag & Lag \\
\hline Bupirimate & 3.68 & 6 & 0.654 & 0.13 & 0.963 & 19 \\
\hline Fenarimol $^{a}$ & 3.69 & 8 & 1.105 & 0.221 & 0.953 & 17 \\
\hline Cadusafos & 3.85 & 5 & 0.952 & 0.19 & 0.988 & 19 \\
\hline
\end{tabular}

Lag: lag effect appearance; 'Linear accumulation for I 5 days only; 'Linear accumulation for 10 days only

\section{Sampling rate and polarities correlation}

For neutral compounds investigated in this study, a quadratic correlation between calculated Rs and log kow has been established. Increasing Rs values were observed with increased log kow followed by a decreasing trend when log kow exceeded 2 (Figure 2). Thomatou et al..$^{5}$ and Shaw et al. ${ }^{8}$ reported a quite similar trend when they studied pesticides with $\log$ kow between 1.78 and 4.0. ${ }^{5,8}$ In addition, this Gaussian-shaped relation was observed with Vrana et al. ${ }^{12}$ for hydrophobic organic compounds such as PAHs and organochlorine pesticides using Chemcatcher passive sampler. ${ }^{12}$ Mazella et al. established also a quadratic regression between log kow and Rs of polar pesticides using POCIS device followed by a plateau for compounds with log kow higher than 2.5 which is in agreement with our results (3). Whereas other studies have reported linear correlation ${ }^{26}$ or no clear trend. ${ }^{27}$

\section{Measurement of the dissipation rates (PRC offloads)}

The sampling rate specific-compound value is essential to calculate the water average concentration. It is determined in the laboratory in controlled conditions of temperature and agitation. But in-situ, these conditions may be different (current more or less strong depending on the flow of the river). In addition, it is possible to observe biofilm formation on the membrane of POCIS. That is why in most cases, Rs lab cannot be used directly to calculate in-situ average concentration, they must be corrected. To correct these Rs lab, one or more performance reference compounds (PRC) is introduced inside the sorbent phase before in-situ exposure. PRCs are non-interfering compounds and whose desorption during the period of exposure can correct in-situ sampling rate. PRC is lost into the surrounding water during the experiment under isotropic conditions exchange, between the elimination rate of PRC and the accumulation rate of analytes. But, the main difficulty is to find compounds that can be desorbed significantly during the exposure periods, which is not easy with a solid receiving phase involving adsorption phenomena as Oasis HLB. Recently, DIA d5 has been introduced as PRC for the analysis of herbicides in surface waters. ${ }^{3}$ For hydrophilic compounds, the use of PRC is more difficult than hydrophobic ones and the uptake of the 
target analytes/elimination of their isotopic labelled analogues from the POCIS sorbent do not often take place under isotropic conditions. ${ }^{28}$ In this paper, in addition to the DIA d5, we evaluated the kinetic desorption of ATR d5 in order to evaluate its behavior in HLB phase as PRC compound. Figure 3 shows the desorption trend of DIA d5 and ATR d5 with time. A significant elimination trend was observed for DIA d5 while, ATR d5 shows increasing/decreasing signals in the analysis probably due to an analytical interference knowing that ATR d5 was not observed in blanks. The loss of PRC from the receiving phase is $95 \%$ of DIA d 5 and $12 \%$ of ATR d5. The elimination rate of DIA d5 $\left(0.14319\right.$ day $\left.^{-1}\right)$ was 22 times higher than ATR d5 (0.006 day 1) (Table 4). Elimination rates constants were calculated using Eq.4 in section 2.1. ${ }^{12}$ For ATR d5, the elimination was questionable and thus it is not considered as an appropriate PRC (Figure 3). For DIA d5 for a certain constant dissipation of PRC under certain condition, a time range of environmental exposure is acceptable to maintain between 20 and $80 \%$ of the total PRC in the sampler sorbent. In our investigation, the residual amount of DIA d5 was within the acceptable range for exposition duration about 25 days.

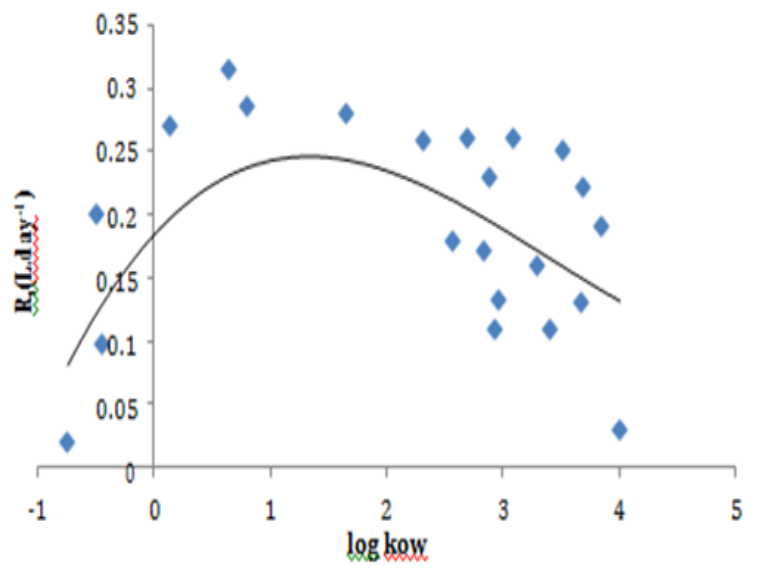

Figure 2 Correlation between sampling rates "Rs (L.day $\left.{ }^{-1}\right)$ ", and hydrophobicity "log kow", for the target pesticides.
-DIADS $\triangle A T R d S$

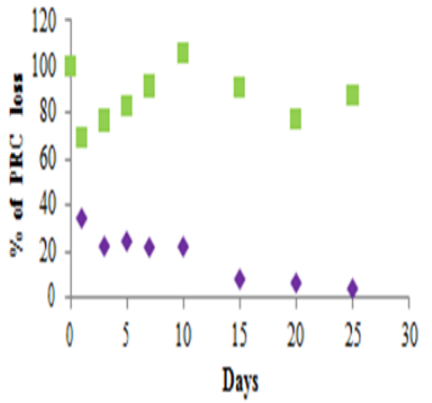

-DIAdS mATRdS

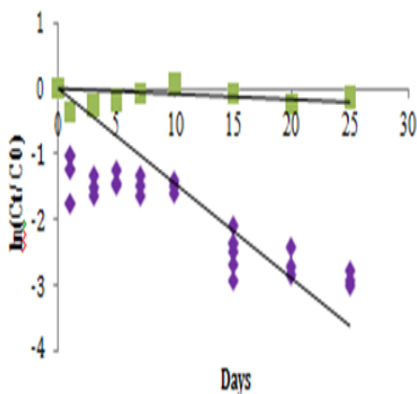

Figure 3 Desorption of selected performance reference compounds during the experiments over 25 days. $C_{t}$ : mass in the sorbent after $t$ days. $C_{0}$ : mass in the sorbent at the beginning ( $\mathrm{t}=0$, amount in blanks).

\section{Comparison with POCIS model compound}

Atrazine is a compound widely used in POCIS calibration experiments. ${ }^{3,4}$ Refferring to literature, atrazine was selected as model compound, because of its linear uptake through POCIS. ${ }^{4}$ Atrazine was included in this study for the purpose of comparison with previous calibration studies; we obtained the same linear trend of atrazine uptake with Rs equal to $0.26 \mathrm{~L} \mathrm{day}^{-1}$ (Figure 4). In similar calibration set-up conditions, Bueno et al. ${ }^{4}$ obtained atrazine Rs value equal to $0.214 \mathrm{~L} \mathrm{day}^{-1}{ }^{4}$ In addition, we found that in different calibration conditions, atrazine showed always too close Rs values. An over view of each experiment condition with corresponding atrazine sampling rate is given in Table 5. In this table we illustrated that Rs values obtained for Atrazine were too close between different calibration experiments. These minor differences may be due to variations in laboratory calibration conditions.

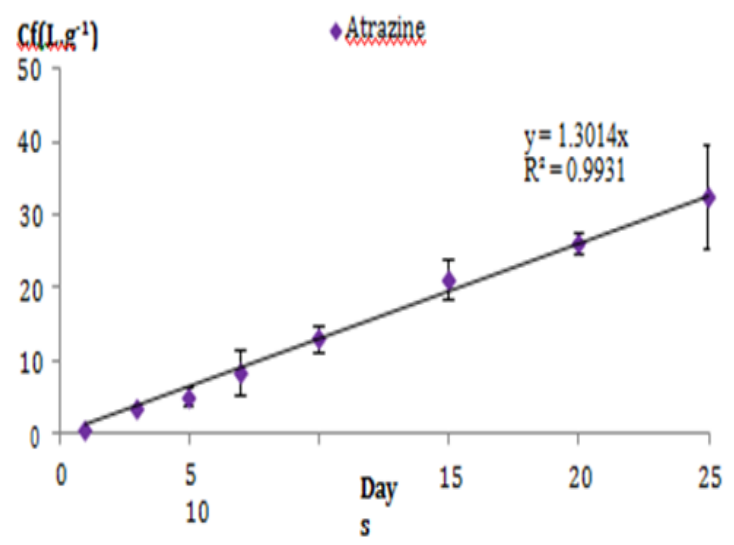

Figure 4 Linear pattern of atrazine compound in the sampler POCIS over a period of 25 days.

Table 4 Summary of PRC exchange kinetic parameters ke obtained from the 25-day calibration. Evaluation of elimination rates ke and the loss percentages of the two PRCs

\begin{tabular}{llll} 
PRCs & $\mathbf{k e}\left(\right.$ day $\left.^{-1}\right)$ & $\%$ of PRC loss & $\mathbf{t}_{1 / 2}$ (day) \\
\hline DIAd5 & 0.14319 & 95 & 5 \\
ATR d5 & 0.00657 & 12 & 106
\end{tabular}

\section{Monitoring results}

The analytical procedure was applied for the detection of the target contaminants in the aquatic environment in a surrounding agricultural land, located at the mount of Lebanon. The samplers POCIS were deployed in river water during a period of 14-15 days from May 2013 to October $2013\left(\mathrm{pH}=6 \pm 1\right.$, conductivity $\left.=35 \pm 2 \mu \mathrm{S} . \mathrm{cm}^{-1}\right)$. The TWA water concentration of each detected compound was estimated from measured concentrations in POCIS using LC-MS analysis. Rs values were obtained for each compound under the experimental conditions previously detailed. The most detected compounds in this period were methidathion, mychlobutanil and propoxur. The TWA concentrations of these compounds were estimated since the uptake rates in the sampler POCIS follow a linear trend during 25 days. We found that propoxur was the only compound whose TWA concentration was 
higher than $10 \mathrm{ng} \mathrm{L}^{-1}$. Some compounds were also detected in the their quantification by POCIS sampling device.

POCIS sorbent phase but the lack of their sampling rates prevents

Table 5 Comparison of some experimental calibration conditions from 1999 until 2012

\begin{tabular}{|c|c|c|c|c|c|c|c|}
\hline $\begin{array}{l}\text { Conditions } \\
\text { of each } \\
\text { experiment }\end{array}$ & Container & Concentration & Conditions & $\mathrm{T}\left({ }^{\circ} \mathrm{C}\right)$ & Duration & Repeatability & $\begin{array}{l}\text { Rs (L } \\
\text { day') }\end{array}$ \\
\hline $\begin{array}{l}\text { Our study } \\
2012\end{array}$ & $\begin{array}{l}\text { Glass beakers } \\
\text { containing } 2 \mathrm{~L} \\
\text { mineral water }\end{array}$ & $0.1 \mu \mathrm{g} \mathrm{L}^{-1}$ & $\begin{array}{l}\text { Water was replaced daily } \\
\text { with freshly spiked water, and } \\
\text { was stirred continuously by } \\
\text { using magnetic stirrers. }\end{array}$ & 20 & 25 days & Triplicate & 0.263 \\
\hline Alvarez et al. ${ }^{12}$ & $\begin{array}{l}\text { Glass beakers } \\
\text { containing IL } \\
\text { drinking water }\end{array}$ & $5 \mu g \mathrm{~L}^{-1}$ & $\begin{array}{l}\text { Water was replaced daily } \\
\text { with freshly spiked water and } \\
\text { was stirred continuously by } \\
\text { using magnetic stirrers. }\end{array}$ & 27 & 56 days & Triplicate & 0.24 \\
\hline Mazzella et al. ${ }^{3}$ & $\begin{array}{l}\text { Tank of } 80 \mathrm{~L} \text { tap } \\
\text { water }\end{array}$ & $\mathrm{I}-2 \mu \mathrm{g} \mathrm{L}^{-1}$ & $\begin{array}{l}\text { Tap water }(\mathrm{pH} \approx 7.3) \\
\text { turbulent conditions using a } \\
\text { peristaltic pump. }\end{array}$ & 17 & 21 days & Duplicate & 0.239 \\
\hline Alvarez et al. ${ }^{12}$ & Aquarium 8L & $10 \mu g \mathrm{~L}^{-1}$ & $\begin{array}{l}\text { Water was replaced daily } \\
\text { with freshly spiked water, and } \\
\text { was stirred continuously by } \\
\text { using magnetic stirrers. }\end{array}$ & - & 5 days & - & 0.24 \\
\hline Bueno et al. ${ }^{4}$ & $\begin{array}{l}\text { Glass beakers } \\
\text { containing } 2 \mathrm{~L} \\
\text { spiked seawater }\end{array}$ & $0.5 \mu g \mathrm{~L}^{-1}$ & $\begin{array}{l}\text { Seawater was replaced daily } \\
\text { with freshly spiked water, and } \\
\text { was stirred continuously by } \\
\text { using magnetic stirrers. }\end{array}$ & 21 & $\begin{array}{l}\text { period of } \\
\text { I,3 and } 7 \\
\text { days }\end{array}$ & Duplicate & 0.214 \\
\hline Lissalde et al. ${ }^{19}$ & $\begin{array}{l}\text { Tank of 80L } \\
\text { freshwater }\end{array}$ & I $\mathrm{mg} \mathrm{L}^{-1}$ & $\begin{array}{l}\text { Tap water }(\mathrm{pH} \approx 7.3) \\
\text { turbulent conditions using a } \\
\text { peristaltic pump. }\end{array}$ & 17 & 24 days & Triplicate & 0.228 \\
\hline
\end{tabular}

\section{Conclusion}

Laboratory calibration experiment based on static renewals under stirred conditions was performed for the calibration of POCIS and for sampling rates determination of the selected pesticides. The stability of all target compounds was investigated and the recovery was $>$ $67 \%$ with relative standard deviation $(\mathrm{RSD})<11 \%$. The calibration revealed linear and integrative uptakes for the target pesticides during 25 days of exposure. A lag phase for the more hydrophobic compounds was observed. Poor correlation between hydrophobicity and sampling rates was observed. However, despite the decreasing in sampling rates with increased log kow, compounds showed linear uptake through HLB phase confirming that POCIS may be used for a wide range of pollutants. Rs values found varied from 0.0186 to $0.316 \mathrm{~L} \mathrm{day}^{-1}$ with $(\mathrm{RSD})<24 \%$. The low Performance Reference Compounds potential was shown for ATR d5 per comparison with DIA d5 according to their trend and to their elimination rate constant

\section{Acknowledgement}

None.

\section{Conflict of interest}

All authors declare that no financial/commercial conflicts of interest.

\section{References}

1. Bliefert C, Perraud R. Environmental chemistry: air, water, soil, waste, De Boeck, France; 2001.

2. Kot A, Zabiegała B, Namieśnik J. Passive sampling for long-term monitoring of organic pollutants in water. $\operatorname{Tr} A C .2000 ; 19(7): 446-459$.
3. Mazzella N, Dubernet JF, Delmas F. Determination of kinetic and equilibrium regimes in the operation of polar organic chemical integrative samplers: Application to the passive sampling of the polar herbicides in aquatic environments. $J$ Chromatogr. 2007;1154(1-2):42-51.

4. Martínez Bueno MJ, Hernando MD, Agüera A, et al. Application of passive sampling devices for screening of micro-pollutants in marine aquaculture using LC-MS/MS. Talanta. 2009;77(4):1518-1527.

5. Thomatou A, Zacharias I, Hela D, et al. Passive sampling of selected pesticides in aquatic environment using polar organic chemical integrative samplers. Environ Sci Pollut R. 2011;18(7):1222-1233.

6. Booij K, Sleiderink HM, Smedes F. Calibrating the uptake kinetics of semipermeable membrane devices using exposure standards. Environ Toxicol Chem. 1998;17(7):1236-1245.

7. Huckins JN, Petty JD, Orazio CE, et al. Determination of Uptake Kinetics (Sampling Rates) by Lipid-Containing Semipermeable Membrane Devices (SPMDs) for Polycyclic Aromatic Hydrocarbons (PAHs) in Water. Environ Sci Technol. 1999;33(21):3918-3923.

8. Shaw M, Negri A, Fabricius K, et al. Predicting water toxicity: Pairing passive sampling with bioassays on the Great Barrier Reef. Aquat Toxicol. 2009;95(2):108-116.

9. Charlestra L, Amirbahman A. Courtemanch DL, et al. Estimating pesticide sampling rates by the polar organic chemical integrative sampler (POCIS) in the presence of natural organic matter and varying hydrodynamic conditions. Environ Pollut. 2012;169:98-104.

10. Bartelt-Hunt SL, Snow DD, Damon-Powell T, et al. Quantitative evaluation of laboratory uptake rates for pesticides, pharmaceuticals, and steroid hormones using POCIS. Environ Toxicol Chem. 2011;30(6):14121420 .

11. Vrana B, Mills GA, Kotterman M, et al. Modelling and field application of the Chemcatcher passive sampler calibration data for the monitoring of hydrophobic organic pollutants in water. Environ Pollut. 2007;145(3):895904. 
12. Alvarez DA, Huckins JN, Petty JD, et al. Tool for monitoring hydrophilic contaminants in water: polar organic chemical integrative sampler (POCIS). Greenwood GMR, Vrana B, editors. Spain: Comprehensive Analytical Chemistry; 2007. 171 p.

13. Li H, Helm PA, Paterson G, et al. The effects of dissolved organic matte and $\mathrm{pH}$ on sampling rates for polar organic chemical integrative samplers (POCIS). Chemosphere. 2011;83(3):271-280.

14. Gunold R, Schäfer RB, Paschke A, et al. Calibration of the Chemcatcher passive sampler for monitoring selected polar and semi-polar pesticides in surface water. Environ Pollut. 2008;155(1):52.

15. Huckins JN, Manuweera GK, Petty JD, et al. Lipid-containing semipermeable membrane devices for monitoring organic contaminants in water. Environ Sci Technol. 1993;27(12):2489-2496.

16. Vrana B, Mills G, Greenwood R, et al. Performance optimisation of a passive sampler for monitoring hydrophobic organic pollutants in water. $J$ Environ Monit. 2005;7(6):612-620.

17. Booij K, Vrana B, Huckins J. Passive Sampling Techniques in Environmenta Monitoring. Greenwood R, Mills G, Vrana B editors. Wilson \& Wilsons, Elsevier; 2007. 486 p.

18. Harman C, Tollefsen KE, Bøyum O, et al. Uptake rates of alkylphenols, PAHs and carbazoles in semipermeable membrane devices (SPMDs) and polar organic chemical integrative samplers (POCIS). Chemosphere. 2008;72(10):1510-1516.

19. Lissalde S, Mazzella N, Fauvelle V, et al. Liquid chromatography coupled with tandem mass spectrometry method for thirty-three pesticides in natural water and comparison of performance between classical solid phase extraction and passive sampling approaches. $J$ Chromatogr A. 2011;1218(11):1492-1502.

20. Booij K, Van Bommel R, Mets A, et al. Little effect of excessive biofouling on the uptake of organi contaminants Semipermeable membrane devices. Chemosphere. 2006;65(11):2485-2492.

21. Huckins JN, Petty JD, Lebo JA, et al. Development of the permeability/ performance reference compound approach for in situ calibration of semipermeable membrane devices. Environ Sci Technol. 2002;36(1):85-91.

22. Ibrahim I, Togola A, Gonzalez C. Polar organic chemical integrative sampler (POCIS) uptake rates for 17 polar pesticides and degradation products: laboratory calibration. Environ Sci Pollut R. 2013;20(6):3679-3687.

23. Vermeirssen ELM, Dietschweiler C, Escher BI, et al. Transfer Kinetics of Polar Organic Compounds over Polyethersulfone Membranes in the Passive Samplers Pocis and Chemcatcher. Environ Sci Technol. 2012;46(12):6759-6766

24. Morin N, Camilleri J, Cren-Olivé C, et al. Determination of uptake kinetics and sampling rates for 56 organic micropollutants using "pharmaceutical" POCIS. Talanta. 2013;109:61-73.

25. Mac Leod SL, McClure EL, Wong CS. Laboratory calibration and field deployment of the Polar organic chemical integrative sampler for pharmaceuticals and personal care products in wastewater and surface water. Environ Toxicol Chem. 2007;26(12):2517-2529.

26. Togola A, Budzinski H. Development of Polar Organic Integrative Samplers for Analysis of Pharmaceuticals in Aquatic Systems. Anal Chem. 2007;79(17):6734-6741.

27. Arditsoglou AD, Voutsa. Passive sampling of selected endocrine disrupting compounds using polar organic chemical integrative samplers. Environ Pollut. 2008;156(2):316-324.

28. Harman C, Brooks S, Sundt RC, et al. Field comparison of passive sampling and biological approaches for measuring exposure to PAH and alkylphenols from offshore produced water discharges. Mar Pollut Bull. 2011;63(5-12):141-148. 